\title{
Evolution of the clinical trial landscape in Asia Pacific
}

This article was published in the following Dove Press journal:

Open Access Journal of Clinical Trials

29 July 2014

Number of times this article has been viewed

\section{Shourav Yathindranath ${ }^{\prime}$ \\ Amar Kureishi ${ }^{2}$ \\ Simranjit Singh ${ }^{3}$ \\ Spencer Yeow ${ }^{3}$ \\ Grace Geng ${ }^{4}$ \\ Karen Wai' \\ Audrey Ho' \\ Elvira Zenaida Lansang' \\ Ken J Lee ${ }^{5}$}

'Feasibility and Site Identification Asia, ${ }^{2}$ Drug Development Asia, ${ }^{3}$ Strategic Planning Asia, Quintiles East Asia Private Limited, Singapore; ${ }^{4}$ People's Republic of China Site Services, Quintiles, Beijing, People's Republic of China; ${ }^{5}$ Asia Site Services, Quintiles East Asia Private Limited, Singapore

Video abstract

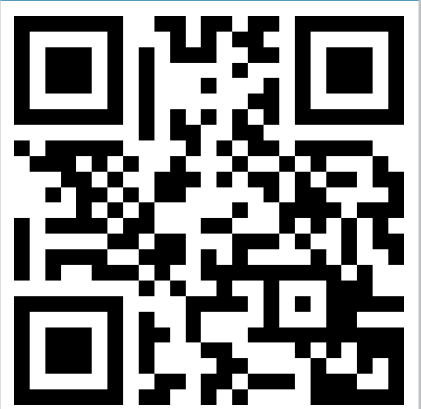

Point your SmartPhone at the code above. If you have a QR code reader the video abstract will appear. Or use: http://dvpr.es/ILL2Mn

Correspondence: Ken J Lee

Quintiles East Asia Private Limited,

79 Science Park Drive, \#06-08, Cintech IV,

Science Park One, Singapore 118264

Tel +65 822804 I5

Email ken.lee@quintiles.com
Introduction: Asia Pacific has and continues to be one of the fastest-growing pharmaceutical markets in the world. This growth has a carry-over effect of driving pharmaceutical research and development investment in the region. Coupled with this, there have been multiple initiatives conducted by governments and other research focused organizations and societies in the region to help support this growth in research. In this report, we discuss the latest developments in pharmaceutical research and development in Asia Pacific and how these various initiatives have made an impact.

Methods: An extensive search of the major clinical trial registries, along with the literature and Internet review of the recent developments in clinical trials, was performed comparing two time periods - 2009-2010 and 2011-2012.

Results: In overall numbers, the clinical trial industry in Asia Pacific has remained stable when comparing the two time periods, with stable volumes of clinical trial numbers and site numbers. However, on closer inspection, a dynamic change in geography, nature, and therapeutic areas of the trials being conducted is observed. Japan, South Korea, People's Republic of China, and Taiwan continue to be major clinical trial destinations. Developing countries, such as Indonesia, Vietnam, and Philippines, have seen rising standards of living and medical care; this is starting to impact their contribution to trials. Also, there are an increasing number of local trials in Asia Pacific with a bigger role being played by Asian pharmaceutical organizations. Consequently, indications under study are now including those with higher prevalence in Asia.

Conclusion: Asia Pacific continues to be an important region for the conduct of clinical trials. With multiple initiatives underway at both local and regional levels aimed at improving the conduct of studies, it is expected that this trend will continue.

Keywords: trends, economic development, health care, emerging markets

\section{Introduction}

Asia Pacific has become an increasingly important region for the clinical trial industry over the past decade. Clinical trial volumes have been steadily growing in Asia Pacific, rising from $5.9 \%$ of the total global volume in $2005-2007$ to $9.7 \%$ in $2011 .^{1}$

Asia-Pacific trial numbers were projected to grow 10\%-15\% annually, compared to just $7 \%$ in the Group of 7 countries (US, UK, France, Germany, Italy, Canada, and Japan) in 2009. ${ }^{2}$ Also, 2 years have elapsed since reports examined Asia-Pacific trends. As changes in Asia occur rapidly, this paper reviews the most recent trends, comparing clinical trial data over the time periods 2009-2010 versus 2011-2012.

With more than $60 \%$ of the world population, Asia offers a large patient pool; most are treatment-naive because of the limited access to affordable medical options. Urbanization has also led to an increase in lifestyle diseases, such as diabetes, obesity, 
hypertension, and various cancers, so it is not surprising that clinical interest in these areas has also increased. Other forces - such as an increase in the pharmaceutical manufacturing capability in Asia, lower operational costs, and emerging health care infrastructures in developing Asian countries have also contributed to fast growth in the pharmaceutical sector and added investment in research and development. ${ }^{2}$

\section{Methods}

In April 2013, clinical trial data was extracted from 15 commercially available online databases for global clinical trials and sites, ${ }^{3}$ including registries in Asia, such as: ClinicalTrials. gov; the Australian New Zealand Clinical Trials Registry; the International Standard Randomized Controlled Trials Number; Clinical Trials Registry, India; Clinical Research Information Service, Republic of South Korea; Japan Primary Registries Network; and the Sri Lanka Clinical Trials Registry.

To analyze the latest trends in Asia Pacific, trial data for two time periods (2011-2012 and 2009-2010) were gathered. Data were analyzed in 2-year blocks to minimize year-on-year variations. Four separate searches were conducted to obtain the study and site data for global and Asia-Pacific clinical trial studies, respectively. A systematic comparison of data was then carried out.

Clinical trials fulfilling the following criteria were included in the data set:

1. All studies with sites in the Middle East, Asia, and Australia were selected and further filtered down to 22 countries in Asia Pacific.

2. Only trials with intervention category "drug" and "biologicals" were included. No behavioral, genetic, devicecentered, procedural, or radiation studies were included.

3. Only Phase I, Phase II, and Phase III trials were analyzed. Phase-hybrid studies were included by grouping them into the later phase of investigation; that is, Phase II/Phase III studies were incorporated into Phase III and Phase I/Phase II into Phase II. Phase IV studies were omitted as they do not require registration.

4. Only industry-linked trials were analyzed.

5. All studies with trial start dates between January 1, 2009 and December 31, 2012 (inclusive) were selected.

6. All studies no longer available, terminated, withdrawn, or suspended were excluded.

All Asia-Pacific clinical studies within these two time periods, meeting the inclusion criteria, were downloaded on April 18, 2013. Global clinical study data, with all the same inclusion criteria barring the regional filter, were downloaded on March 8, 2013. After the filtering criteria were set, the following data were extracted in the form of Microsoft Excel worksheets and analyzed:

- Official study title

- Study identification number

- Study therapeutic area

- Indication(s) under study

- Phase of the study

- Study status

- Sponsor company

- List of countries where study was initiated The clinical site data were obtained in a similar manner. All Asia-Pacific project sites registered within the two time periods, meeting the criteria described below, were downloaded on April 5, 2013.

1. All sites that conducted trials in the Middle East, Asia, and Australia during these time periods were selected and further filtered down to 22 countries in Asia Pacific.

2. Only sites conducting trials with intervention category "drug" and "biologics" were included.

3. Only sites conducting Phase I, Phase II, and Phase III trials were analyzed. Phase-hybrid studies were included by grouping them into the later phase of investigation; that is, Phase II/Phase III studies were incorporated into Phase III and Phase I/Phase II into Phase II. Phase IV studies were omitted as they do not universally require registration.

4. Sites with industry-linked trials were focused on.

5. All sites that had trial start dates between January 1, 2009 and December 31, 2012 (inclusive) were selected.

6. All sites with studies that were no longer available, terminated, withdrawn, or suspended were excluded. The data extracted for the site analysis included:

- Site name

- Site city

- Country of location

- Number of clinical trials conducted

- Study titles

- Study ID number

- Study design

- Trial status

- Therapeutic areas

- Indications

- Sponsor/collaborator list

\section{Results}

From the data gathered and analyzed, it was observed that there was a $11.65 \%$ increase in global clinical trial volume from 2009-2010 to 2011-2012, with more than 
one-fourth $(26.36 \%)$ of the total number of clinical trials in the past 4 years being conducted in Asia Pacific. Over the two time periods, clinical trial numbers in Asia have been relatively stable with only an increase in Phase I trials (Figure 1). Despite the stability of trial numbers for Asia Pacific as a region, there are differing trends in every country with regard to the phase and number of clinical trials (Figure 2).

There was an increase in the number of clinical trials conducted in countries, such as Vietnam, New Zealand, South Korea, and Japan. A particularly large percentage increase was observed in Vietnam mainly in the Phase III trials, albeit with a small baseline number of studies in 2009-2010. South Korea and Japan showed similar trends of an increase in the number of Phase III trials. South Korea was seen to have a large rise in Phase I studies; this was also seen to a lesser extent in the People's Republic of China, Japan, India, and Taiwan. Southeast Asia (consisting of Indonesia, Malaysia, Philippines, Singapore, Thailand, and Vietnam) exhibits a decline in the total number of studies, with a $19.46 \%$ decrease in the numbers. This is driven by the collective fall of Phase III studies.

Another characteristic reviewed was the geographic scope of the trial (global or local). Global trials here are defined as multicenter trials conducted concurrently in two or more countries, while local trials are primarily placed in one country.

By comparing global trials and local trials conducted within the two time periods, a rising trend for local studies is observed (Figure 3). The increase is driven by the growing number of local trials conducted in Japan, South Korea, and the People's Republic of China. One country to note is India, where global trial numbers decreased by almost $35 \%$. Looking at the total number of initiated sites within the

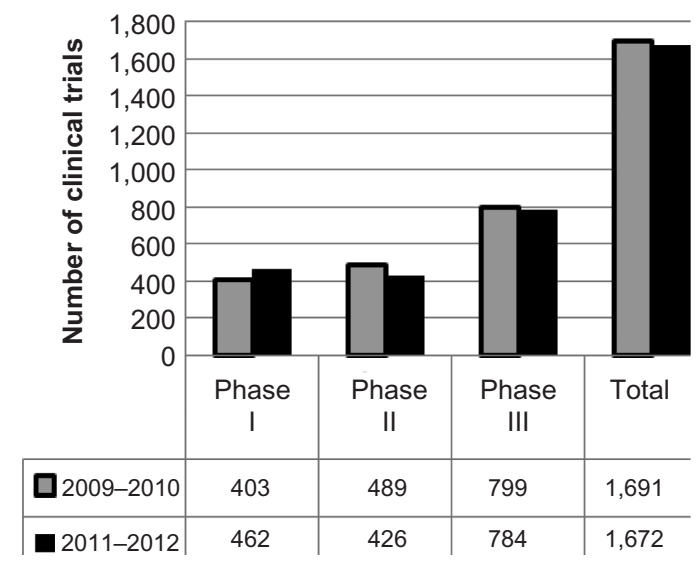

Figure I Number of clinical trials by phase; $2009-2010$ versus $201 \mathrm{I}-2012$. two time periods for each country, we see a decline in the total number of sites (Figure 4).

Japan shows a marked increase in site numbers. Emerging markets like Bangladesh, Vietnam, Sri Lanka, and Cambodia have opened new prospects for clinical trials, with the establishment of new sites in these developing countries.

The shift in trials is not only observed over geographies, but also in major indications. The top 20 indications are listed in Table 1. Diabetes is still the most investigated indication, though there has been a shift toward others. There is an increase in the number of trials for hepatitis $\mathrm{C}$ and chronic obstructive pulmonary disease. Rheumatoid arthritis trials are on the decline, with indications such as gastric cancer, inflammatory bowel disease, hypertension, and depression on the rise. The top 20 indications account for approximately $30 \%$ of the total trials conducted.

A comparison of the top 25 sponsors for studies over 2009-2010 and 2011-2012 was also done. Shown in Table 2, the data demonstrate that multinational pharmaceutical companies dominate with the largest number of trials. Out of the top 25 sponsors, 15 (60\% of the sponsors) were featured within the first one-half of the Pharma Exec 2011 list of top 25 pharmaceuticals worldwide in 2009-2010. This rose to 16 companies in 2011-2012. ${ }^{4} \mathrm{~A}$ rise in the number of Asian pharmaceutical sponsors (companies with their headquarters in Asia Pacific) is also observed with seven companies in the top 25 in 2011-2012 versus six in the previous period.

\section{Discussion}

\section{Increase in Phase I trials}

Data gathered indicate a steady increase in the number of Phase I trials placed in Japan, Singapore, South Korea, Taiwan, India, and the People's Republic of China. This emerging trend may be related to the lower cost of conducting Phase I trials in Asia Pacific, compared to the US or Europe. This can be verified from data extracted from IMS GrantPlan ${ }^{\circledR}$ (IMS Health Incorporated, Danbury, CT, USA), a benchmark for industry costs that are recognized as fair market value for trials. For example, the cost per subject predicted by GrantPlan ${ }^{\circledR}$ for conducting a complete clinical trial for chronic rheumatoid arthritis in the US is almost three times the cost of conducting the same trial in South Korea or Singapore. This growth may also be driven by the increasingly active local pharmaceutical industry that may choose to run early phase studies within their country of origin. The rise in Phase I studies is also reflected in the increase in healthy volunteer indication studies over the two time periods (Table 1). 


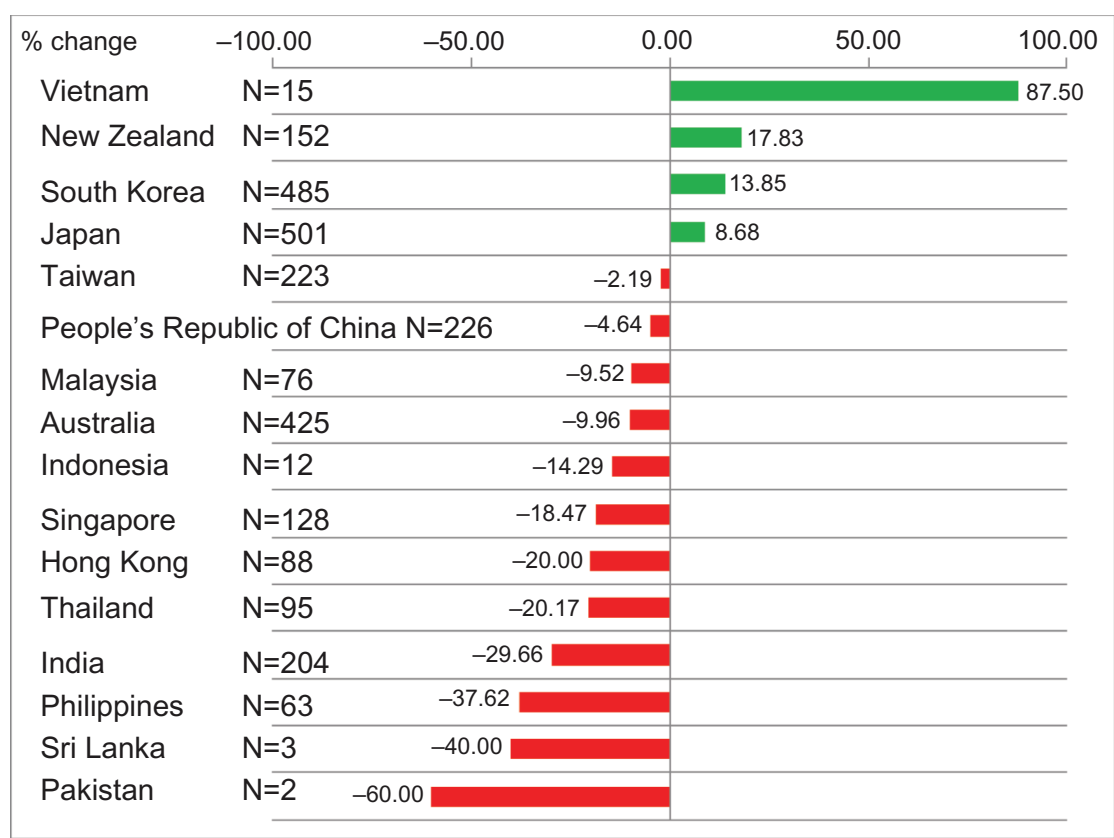

Figure 2 Changes in number of clinical trials by percentage.

Note: The percentages seen in the bar graphs represent \% change in total number from $201 \mathrm{I}-12$ versus $2009-10$.

\section{Comment on Asia's growth}

Asia-Pacific clinical trial numbers have been stable over the past few years. This is expected because Asia Pacific, as a region, has been expanding its pharmaceutical and health care sectors, and avenues for both pharmaceutical drug sales as well as clinical studies have been evolving. Contract manufacturing organizations have been developing their manufacturing capabilities and strengthening regulatory practices. The developing countries offer the advantages of lower operational costs, large untapped patient pools with rising health care awareness, and patient drug naivety, all contributing factors to initiation of new sites and clinical trials. ${ }^{2}$

Other factors influencing this trend include ethnogenetic factors that provide a large and diverse patient pool, increasing medical knowledge and implementation of countryspecific International Conference on Harmonisation-Good Clinical Practice guidelines by most countries. ${ }^{5}$

Economic and political factors, such as trade agreements between countries, also have an impact on easing trial registration and timelines, thus affecting trial numbers.

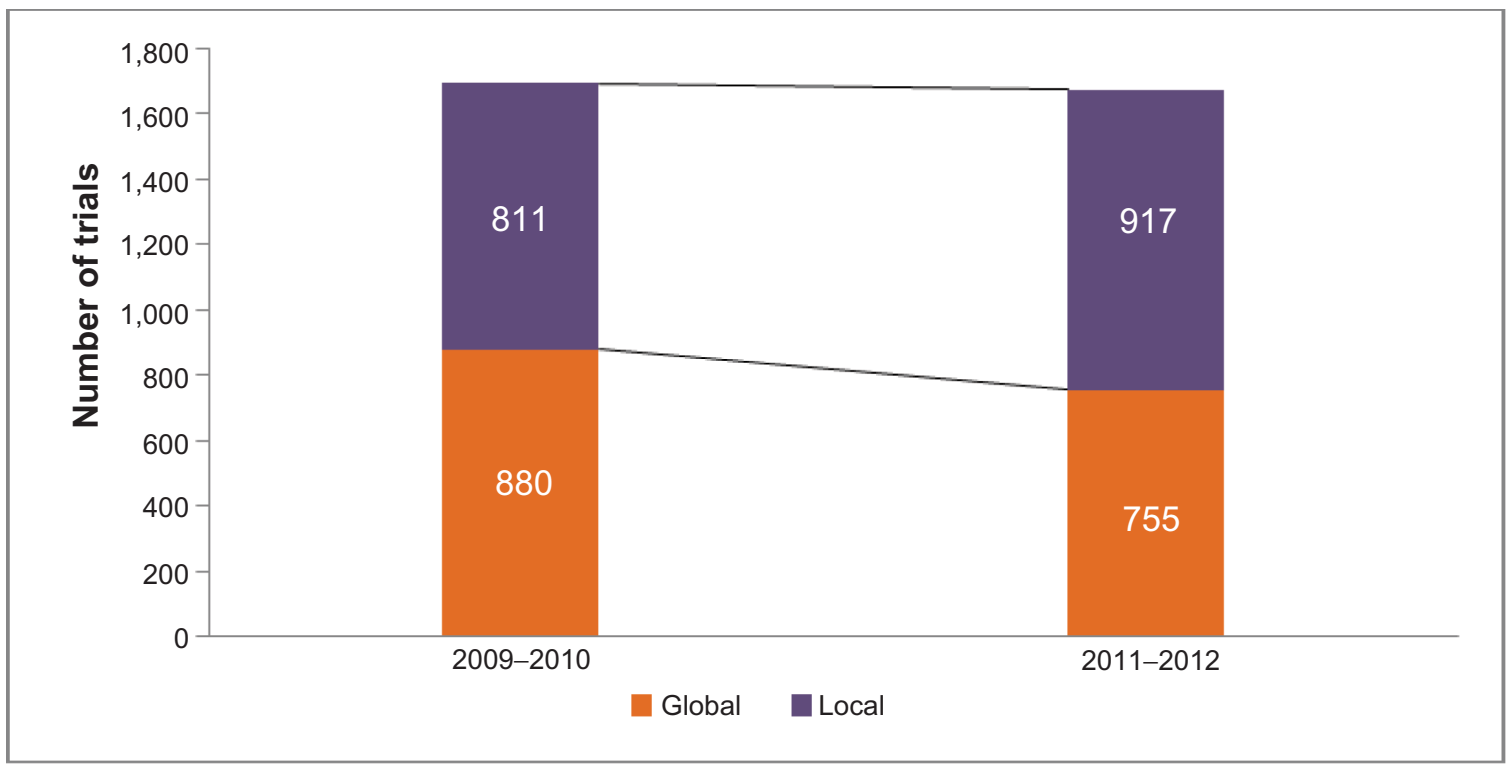

Figure 3 Global versus local trials in Asia Pacific; 2009-2010 versus 20I I-2012. 


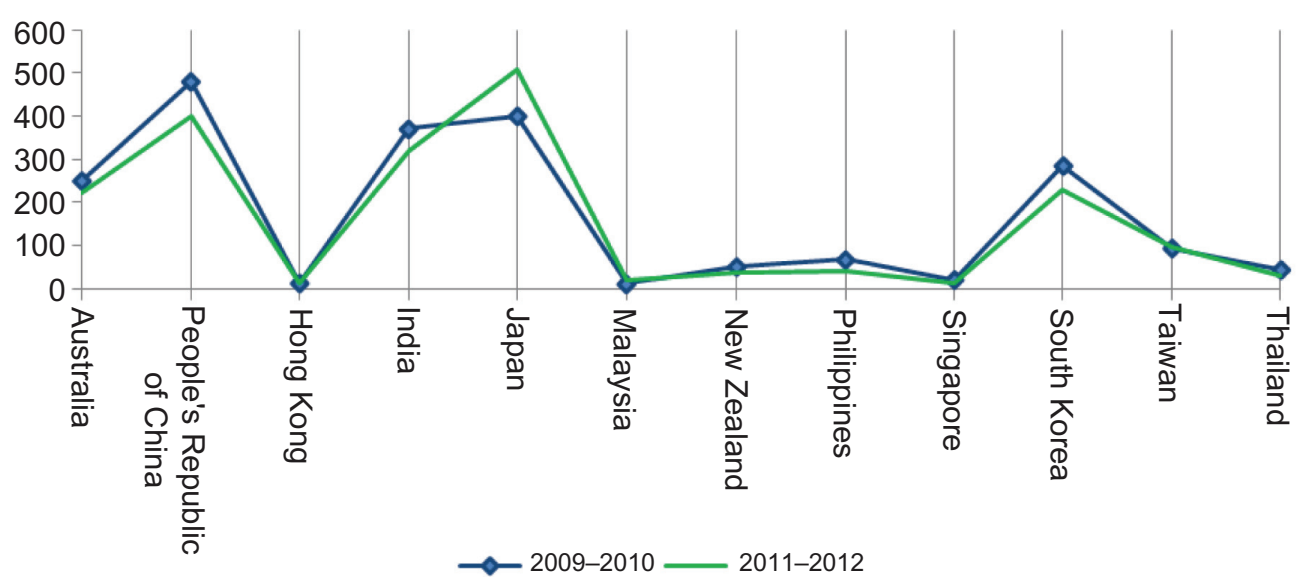

Figure 4 Active sites per country; 2009-20I0 versus 20II-20I2.

For example, Japan, South Korea, and the People's Republic of China have established a tripartite partnership, with a common regulatory body in the works, in recognition of their ethnic, genetic, and economic similarities.

To factor in all these aspects, we attempted to conduct country-specific analyses.

\section{Australia}

Australia, with its population of 23 million, has a gross domestic product (GDP) per capita of US\$65,642. In 2012, it had 425 clinical trials and 224 sites. $^{3}$

Table I Top 20 indications according to trial numbers

\begin{tabular}{|c|c|c|c|}
\hline \multicolumn{2}{|l|}{ 2009-2010 } & \multicolumn{2}{|l|}{$2011-2012$} \\
\hline Indication & $\%$ & Indication & $\%$ \\
\hline Diabetes, type 2 & 7.04 & Phase I healthy volunteers & 6.86 \\
\hline Phase I healthy volunteers & 4.75 & Diabetes, type 2 & 5.21 \\
\hline COPD & 3.20 & COPD & 3.43 \\
\hline Rheumatoid arthritis & 2.47 & Hepatitis C & 2.15 \\
\hline Non-small-cell lung cancer & 1.83 & Rheumatoid arthritis & 2.06 \\
\hline Hypertension & 1.55 & Hypertension & 1.55 \\
\hline Schizophrenia & 1.14 & Schizophrenia & 1.51 \\
\hline Breast cancer & 1.14 & Non-small-cell lung cancer & 1.46 \\
\hline Influenza & 1.01 & Major depressive disorder & 1.01 \\
\hline Chronic hepatitis B & 0.96 & Breast cancer & 0.82 \\
\hline Hepatitis C & 0.91 & Multiple myeloma & 0.73 \\
\hline Alzheimer's disease & 0.82 & Alzheimer's disease & 0.69 \\
\hline Hepatocellular carcinoma & 0.82 & Gastric cancer & 0.64 \\
\hline Prostate cancer & 0.64 & Prostate cancer & 0.55 \\
\hline Venous thromboembolism & 0.55 & Cancer & 0.55 \\
\hline Cancer & 0.50 & Fasting & 0.50 \\
\hline Essential hypertension & 0.41 & Psoriasis & 0.50 \\
\hline Metastatic colorectal cancer & 0.41 & Epilepsy & 0.50 \\
\hline Multiple myeloma & 0.41 & Crohn's disease & 0.50 \\
\hline Neoplasms & 0.41 & Hypercholesterolemia & 0.41 \\
\hline
\end{tabular}

Note: Figures shown as a percentage of total number of trials in APAC for each period (2009-20I0 versus 20I I-20I2).

Abbreviations: COPD, chronic obstructive pulmonary disease; APAC, Asia Pacific.
Australia achieved significant clinical research growth over the past 20 years, but it has been facing a decline in the past 2 years. This trend can be observed from the decreasing number of clinical studies and participating sites placed in the country. There are a number of factors that have contributed to this decline: the rising cost of conducting clinical trials; competition posed by emerging countries offering low-cost Phase II and Phase III trials; and low enrollment rates in Australian trial centers. ${ }^{6}$ The sparse, distributed population of Australia limits the number of patients that a site can recruit, requiring more sites to match enrollment targets. Also, the patient population of certain therapeutic areas has been saturated with little capability to supply new patients. ${ }^{6,7}$ The tough atmosphere for government funding, increasing cost of conducting clinical trials, pharmaceutical companies investing lower budgets for clinical research, and the strong Australian dollar have together reduced the competitiveness of Australia despite the high quality of its sites. ${ }^{8}$ However, Australia is likely to remain a stable contributor with a number of highly qualified sites and well-trained investigators for conducting trials.

\section{People's Republic of China}

The People's Republic of China has a population of 1.35 billion and a GDP per capita of US\$6,075. In 2012, there were 226 clinical trials and 400 sites. $^{3}$

The People's Republic of China is an important market for clinical trials, conducting a consistent $13 \%$ of trial numbers over the past 4 years with an increasing number of local trials being conducted. Investments by multinational pharmaceuticals and alliances forged between local Chinese and Asian contract research organizations (CROs) have offered mutual benefit and developmental services. ${ }^{2}$ The People's Republic of China Food and Drug Administration (FDA) also issued 
Table 2 Top sponsors according to the number of studies each conducted in Asia Pacific; 2009-2010 versus $2011-2012$

\begin{tabular}{|c|c|c|c|}
\hline \multicolumn{2}{|l|}{$2009-2010$} & \multicolumn{2}{|l|}{$2011-2012$} \\
\hline Sponsor & \# of studies & Sponsor & \# of studies \\
\hline GlaxoSmithKline & 134 & Novartis & 117 \\
\hline Pfizer & 117 & GlaxoSmithKline & 94 \\
\hline Novartis & 114 & Pfizer & 84 \\
\hline Boehringer Ingelheim Pharmaceuticals & 61 & Eli Lilly and Company & 76 \\
\hline AstraZeneca & 54 & Merck & 58 \\
\hline Hoffmann-La Roche & 49 & Hoffmann-La Roche & 57 \\
\hline Astellas Pharma Inc. & 48 & Boehringer Ingelheim Pharmaceuticals & 57 \\
\hline Sanofi & 48 & AstraZeneca & 41 \\
\hline Merck & 47 & Astellas Pharma Inc. & 35 \\
\hline Eli Lilly and Company & 46 & Sanofi & 35 \\
\hline Bristol-Myers Squibb & 40 & Bristol-Myers Squibb & 34 \\
\hline Bayer & 39 & Takeda Global Research and Development Center, Inc. & 33 \\
\hline Novo Nordisk & 32 & Janssen Research and Development, LLC & 29 \\
\hline Eisai Inc. & 23 & Amgen & 29 \\
\hline Otsuka Pharmaceutical Co, Ltd & 22 & Eisai Inc. & 28 \\
\hline Amgen & 22 & Novo Nordisk & 27 \\
\hline Janssen Research and Development, LLC & 19 & Bayer & 27 \\
\hline Celgene Corporation & 17 & IPCA Laboratories Ltd & 26 \\
\hline AbbVie & 17 & Gilead Sciences & 23 \\
\hline Dr Reddy's Laboratories Limited & 15 & Mitsubishi Tanabe Pharma Corporation & 21 \\
\hline Biogen Idec & 14 & UCB, Inc. & 18 \\
\hline Kyowa Hakko Kirin Company, Limited & 12 & Hanmi Pharmaceutical Co, Ltd & 17 \\
\hline Allergan & 12 & Chong Kun Dang Pharmaceutical & 17 \\
\hline Chong Kun Dang Pharmaceutical & 11 & Genentech & 16 \\
\hline ImClone LLC & 11 & Yuhan Corporation & 16 \\
\hline
\end{tabular}

new guidelines to eliminate the bottleneck posed by the clinical trial process. There has been a redraft of the Phase I-approval guidelines, using several international guidelines as benchmarks as well as the simplification of Phase II registration requirements. The People's Republic of China is also collaborating with other countries in an effort to harmonize clinical trials. The Cross-Strait Agreement with Taiwan ${ }^{5}$ was set up to facilitate system and regulation exchanges between the countries. The proposed tripartite cooperation with the People's Republic of China, South Korea, and Japan seeks to exchange clinical data and study the effect of ethnic factors in clinical studies. These efforts could lead to probable increments in trial numbers and standards in these countries.

\section{India}

With its population of 1.21 billion, India's GDP per capita is US\$1,592. The number of clinical trials in 2012 was 204; there were 321 sites. $^{3}$

A significant change for India has been seen in recent times. The clinical trial sector saw a 30\% growth from 2004-2009 with an almost equal growth in trial numbers annually. ${ }^{9}$ However, in the most recent period, a downward trend in clinical trial projects and site numbers is observed, largely due to the current ambivalent regulatory environment. This environment has been driven by recent public concern (2011-2012) featured prominently in the media about the safety and ethical nature of clinical trials. As of February 2013, changes in regulations with regards to adverse events, compensation, and ethics committee registration have been issued. ${ }^{10}$ Unannounced audits of sites and subjects, collation of Significant Adverse Events and their compensation forms, stringent review and approval for informed consent drafts, and greater liability on the sponsor and the CROs have all been proposed in a bid to increase safety. ${ }^{2}$ However, considering the prospects that India offers with its large population, large pharmaceutical market, and low operational cost, the sponsors and CROs are likely to comply with these new regulations for safety and will eventually help India regain its leadership role in clinical trials.

\section{Indonesia}

With a population of 237 million, Indonesia has a GDP per capital of US\$3,592. In 2012, there were 12 clinical trials at nine sites. ${ }^{3}$

Indonesia, being the fourth most populous country (most residents have been elevated to the middle class because of 
economic growth), has the potential to develop into a large clinical trial center. Despite efforts to improve drug development and medical access, it is evident by the decrease in trial numbers and sites in 2011-2012 that challenges to operate still exist. The main challenges include limitations to the resources provided by the government, regulations such as the Standard Material Transfer Agreement, which restricts the transfer and use of biological specimens, and a ministerial decree (number 732) that restricts clinical trials to protect the people and to increase transparency. ${ }^{11}$ However, given the potential of the pharmaceutical market there, it is likely that policies might be reversed, and investment patterns will change in the future.

\section{Japan}

With a population of 126 million, Japan had a population of GDP per capita of US \$46,736 in 2012. There were 501 clinical trials and 507 sites. $^{3}$

Japan is an important market in Asia Pacific, conducting more than $29.9 \%$ of trials in 2011-2012 alone and accounting for $26.1 \%$ of the sites involved for that period. In the past, conducting clinical trials in Japan was fraught with challenges, due to the issues with drug lag, high cost of clinical trials, and the relatively poor infrastructure. ${ }^{12}$ To buck the trend, the Japanese government made concentrated efforts through a series of initiatives to increase the number of trials placed. In 2005, a special committee was created to allow for fast-track drug approval, and additional review staff at the Pharmaceutical and Medical Devices Agency were hired. Also, the drug application requirements were relaxed to encourage marketing of new drugs. ${ }^{12}$ In 2007, the New Drug Industry Vision was commissioned by the Japan Ministry of Health, Labour, and Welfare to eliminate drug lag and propel Japan to a position on par with Western countries by 2011. The program "Coordination, Support and Training Program for Translational Research" was also initiated in 2007 by the Ministry of Education, Culture, Sports, Science, and Technology to help fund and commercialize products of biotech companies. ${ }^{13}$

The Pharmaceutical and Medical Devices Agency in 2008, agreed to allow global clinical data, as long as safety studies in Japanese patients were carried out, in all drug applications. ${ }^{12}$ To speed up the introduction of foreign drugs into Japan, the Ministry of Health, Labour, and Welfare in February 2010 launched the Review Session for Highly Needed Unlisted Drugs/Non-Indication Use initiative, to evaluate a list of drugs that had not yet obtained approval. In June 2010, the government sprang into action to resolve the drug lag through the implementation of a new system, in which approximately 200 medical institutions were empowered to prescribe unlisted drugs/devices to meet the dire needs of high-risk patients by $2012 .^{13}$

All these measures have likely led to an increase in drug-development activity over the past 2 years in Japan. It is likely that these measures will continue to benefit Japan in the future, further increasing the growth and efficiency of its clinical trial industry.

\section{Malaysia}

With its population of 29 million, Malaysia's GDP per capital is US\$10,380. In 2012, there were 106 clinical trials and 20 sites. $^{3}$

Malaysia saw a decrease in the number of clinical trials over the last 2 years but with relatively stable site numbers. In view of this, the Malaysian government has set up an entry point project aimed at creating a supportive ecosystem to grow clinical research. One of the key initiatives here was the establishment of Clinical Research Malaysia, a not-forprofit government site management organization. Clinical Research Malaysia will facilitate clinical trial standards, such as GCP-certified investigators, potential recruitment sites, transparency in financial processes, and oversight on conduct of industry-sponsored research in government hospitals. The function will build on the foundation established by the Clinical Research Centres that has been established at 27 sites across the country. ${ }^{14}$

The clinical research entry point project is one part of 12 National Key Economic Areas that represent economic opportunities targeted for improvement by the Malaysian government. With such strong efforts in progress, it is anticipated that Malaysia, with its already well-established medical infrastructure, will contribute more to clinical trials in Asia.

\section{Philippines}

The Philippines has a population of 97 million and a GDP per capital of US\$2,614. In 2012, there were 63 clinical trials and 42 sites. $^{3}$

The Philippines saw a decrease in the number of clinical trials over the last 2 years because of a fall in Phase III numbers. Phase III studies are the main category of trials being conducted in the Philippines, with most being global trials. Site numbers have also decreased over the last 2 years.

The Department of Health has included provisions in the Medicines Act that mandate pharmacovigilance which requires reporting of events online and quarterly monitoring. It also includes a framework for an advisory system, 
a pharmacovigilance centre and the building of a network of reporters. ${ }^{15}$ These measures, along with a pharmaceutical market size of US\$300 million and health expenditure reaching 3.2\% of its GDP, may position the Philippines as a large potential for expansion of trials.

\section{Republic of South Korea}

After experiencing almost $10 \%$ growth in its pharmaceutical sector in 2009 , South Korea has become a significant contributor to Asian clinical trials and pharmaceutical research and development, closely competing with Japan. ${ }^{2}$ South Korea demonstrated a growth of $13.85 \%$ in the number of trials over the second time period (2011-2012) while exhibiting a decline in site numbers.

With a large population at 50 million, a strong economy (GDP per capita at US\$23,113), and advanced medical infrastructure, Korea is an attractive market for clinical trials. In 2012, there were 485 clinical trials and 231 sites. $^{2}$ The streamlining of regulatory procedures by Korea's Ministry of Food and Drug Safety has reduced approval timelines to around 30 days, comparable to Western countries. Patient recruitment is a major differentiator for South Korea; there are competent, welltrained investigators who recruit subjects from their own pool of patients, utilizing advertisements and advanced technology for uncommon disorders. ${ }^{16}$ There is also active development of centers for clinical studies and efforts to promote multinational studies by the Korean National Enterprise for Clinical Trials. ${ }^{17}$ All these efforts may take credit for the rise in speed and efficiency of conducting trials. South Korea is likely to advance the clinical trial industry with this efficiency, unless a bottleneck is reached in terms of sites and infrastructure.

\section{Singapore}

With its population of 5 million, the GDP per capita of Singapore is US\$50,323. In 2012, the number of clinical trials held was $128 ; 15$ sites were used. ${ }^{3}$

Singapore, which had significant growth previously, faces increasing competition from its neighbors and is limited by a small population. A strong economy, diverse population, and easy access to high-quality medical facilities have made it an important country for clinical studies; however, there has been a decline in the number of studies and project sites in 2011-2012. Both research and development in clinical studies are still strong in certain segments, with a steady number of Phase I trials from 2009-2010 to 2011-2012. The strategic focus on early stage clinical trials by the Singapore government and investments by multinational pharmaceuticals in research and development facilities is a key factor in sustaining this trend. ${ }^{18}$

Singapore remains the focal point of regulatory development. Being the secretariat for the Asia Pacific Economic Cooperation Coordinating Centre for Good Clinical Practices, it has undertaken initiatives for training clinical personnel in good clinical practices and the overall promotion of an environment that is conducive to the conduct of regional multicenter clinical studies. ${ }^{2}$ Given these factors, it is likely that Singapore will remain an important Asian location for early phase trials.

\section{Taiwan}

With its population of 23 million and a GDP per capita of US\$20,328, Taiwan had 223 clinical trials in 2012; there were 97 sites. $^{3}$

Taiwan is an important node in the Asian clinical trial network, conducting about $13.3 \%$ of trials in 2011-2012 with about 97 sites during that time period. There has, however, been a small decline in clinical trial numbers, due to decreasing Phase II and III trials compensated only slightly by an increase in Phase I trials placed in Taiwan from 2011-2012. Nevertheless, Taiwan is likely to continue to be an important destination due to a large medical research base, driven by high-tech facilities and large pool of local talent. Taiwan also provides an environment conducive to emerging local CROs through tax incentives to encourage employment. ${ }^{2}$

Other initiatives have also been implemented by the Taiwan Department of Health to replace local registration requirements to meet international standards and to establish the Centre for Drug Evaluation, to assist in drug application reviews and the drafting of guidelines, and to provide a nongovernmental, nonprofit consultation service to local pharmaceutical companies. ${ }^{19}$ The Cross-Strait Medical and Healthcare Cooperation Agreement was signed in December 2010 between Taiwan and the People's Republic of China, in an attempt to facilitate exchanges and to help harmonize their respective clinical trial systems, regulations, implementation, patient protection, and approval procedures. ${ }^{20}$ It is likely that these measures might spark an increase in trial numbers, and Taiwan may even become a launching pad for companies looking to invest in the People's Republic of China.

\section{Vietnam}

Vietnam's population is 90 million; its GDP per capita is US\$1,527. In 2012, there were 15 clinical trials and four sites. ${ }^{3}$ 
In 2011-2012, there was a large increase in the number of clinical trials conducted in Vietnam, despite relatively small baseline numbers. This is in spite of Vietnam's health care system being underdeveloped and a clinical trial industry that is still in its infancy. In Vietnam, the Ministry of Health $(\mathrm{MoH})$ regulates hospitals and clinical activities. Clinical trials require approval from both the $\mathrm{MoH}$ and the Ethics Committee. The $\mathrm{MoH}$ recently issued guidelines for CROs and site management organizations to improve monitoring quality and to provide for adequate insurance to ensure subject safety. ${ }^{21}$ Vietnam has a large and fast growing population estimated to be 96 million by 2019 . The total medicine consumption value is close to US\$2.5 billion in 2011 with less than half coming from domestic medicine. Analysts forecast the pharmaceutical market in Vietnam to grow at a compound annual growth rate of 18.5 percent over the period 2011-2015. ${ }^{22}$ Government guidelines, together with these factors, may assist in developing this emerging country into a productive clinical trial zone.

\section{Limitations of data}

The data presented here have certain limitations that cannot be corrected in the analysis:

- The time periods chosen for the analysis are brief and cannot wholly represent the dynamic clinical trial trends. However, these time periods were chosen to investigate recent developments in a rapidly evolving region, both positive and negative, which might potentially impact future trials.

- Ambiguity and redundancy are present in the clinical site data, where the same hospital has multiple names due to misspelling. In addition, some hospitals have branches in different cities that have not been indicated.

- Clinical study records that do not list site-specific names are not included in the site search.

- There is redundancy in therapeutic area data, where the same project may have been reflected in more than one therapeutic area. There are instances of mislabeling of therapeutic areas also, all of which were ignored due to the volume of data processed.

- The completeness of the data is dependent on compliance of data entry to the searched registries.

\section{Conclusion}

The clinical trial industry in Asia Pacific has remained steady over the past few years, with stable volumes of clinical trial and site numbers. However, there are dynamic trends in geography, nature, and therapeutic areas of the trials being conducted. Major countries for trials, ie, Japan, South Korea, the People's Republic of China, and Taiwan, continue to be popular clinical trial destinations considered by the sponsors and CROs. Developing countries, such as Indonesia, Vietnam, and the Philippines, have seen rising standards of living and medical care. They may soon be in the position to develop this industry further, providing large numbers of sites, patients, and trials.

Another important change to note is the shift toward local trials in Asia Pacific. A larger number of trials are being carried out by Asian pharmaceuticals with indications under study shifting to those with higher Asian incidences. This indicates the growing focus on regional diseases and drug development.

These trends along with changing political and economic factors will likely continue to drive the importance of the Asia Pacific region in the clinical development landscape.

\section{Disclosure}

The authors work for Quintiles, a provider of clinical trial services for biopharmaceutical companies worldwide. With regard to this specific paper, the authors report no conflicts of interest in this work.

\section{References}

1. Karlberg JPE. The establishment of emerging trial regions. Clinical Trial Magnifier. 2011;4(1):7-23.

2. Price Waterhouse Coopers. The Changing Dynamics of Pharma Outsourcing in Asia: Are You Readjusting Your Sights? 2008. Available from: https://www.pwc.be/en/pharma/The-changing-dynamics-ofpharma-outsourcing-in-Asia.pdf. Accessed April 8, 2013.

3. "Infinata," Available: http://www.infinata.com/biopharma-solution/byproduct/biopharm-clinical.html. [Accessed April 8, 2013].

4. Pharmaceutical Executive Magazine [homepage on the Internet]. Pharm Exec 50: Growth from the Bottom Up; 2012. Available from: http://www. pharmexec.com/pharmexec/Top+Feature/Pharm-Exec-50-Growth-fromthe-Bottom-Up/ArticleStandard/Article/detail/773562. Accessed April 8, 2013.

5. Louisa M, Takeuchi M, Setiabudy R, Nafrialdi, Takeuchi M. Current status of phase I clinical trials in Asia: academic perspectives. Acta Med Indones. 2012;44(1):71-77.

6. Medicines Australia. Keeping Clinical Trials in Australia: Why Action is Needed Now. Medicines Australia Occasional Paper Series. Deakin, Australian Capital Territory: 2011. Available from: http:// medicinesaustralia.com.au/files/2011/02/Occasional-Paper-3-ClinicalTrials.pdf. Accessed April 8, 2013.

7. Australian Government. Clinically Competitive: Boosting the Business of Clinical Trials in Australia. Clinical Trial Action Group Report. Canberra, Australian Capital Territory: Australian Government; 2011. Available from: http://www.innovation.gov.au/Industry/Pharmaceuticals andHealthTechnologies/ClinicalTrialsActionGroup/Documents/Clinical_ Trials_Action_Group_Report.pdf. Accessed April 8, 2013.

8. The Trials of Clinical Trials [webpage on the Internet]. Kingston, Australian Capital Territory: Australian Medical Association; 2012 [cited June 3, 2012]. Available from: https://ama.com.au/ausmed/trials-clinical-trials. Accessed April 8, 2013. 
9. Federation of Indian Chambers of Commerce and Industry. The Glorious Metamophosis: Compelling Reasons for Doing Clinical Research in India. 2009.

10. Post stringent norms, clinical trials in India plummet [webpage on the Internet]. Chennai City, India: The Hindu; April 21, 2013. [cited mmm dd, yyyy]. Available: http://www.thehindu.com/sci-tech/health/policyand-issues/post-stringent-norms-clinical-trials-in-india-plummet/ article4639976.ece. Accessed May 5, 2013.

11. Purwadianto A. Bioethics Issues in Clinical Trials and Its Challenges in Indonesia. Brussels, Belgium: European Commission; 2012. Available from: http://ec.europa.eu/bepa/european-group-ethics/docs/pdf/ agus_purwadianto_\%28indonesia\%29.pdf. Accessed April 8, 2013.

12. Sinha G. Japan works To shorten "drug lag," boost trials of new drugs. J Natl Cancer Inst. 2010;102(3):148-151.

13. Tsukamoto E, Tripathi S. Japan's Drug Lag and National Agenda. Skokie, IL, USA: Biomedical Consulting International, Inc.; 2011. Available from: http://www.biomedconsult.com/201101focusjapan. pdf. Accessed April 8, 2013.

14. Malaysia Government [homepage on the Internet]. EPP 2: Creating Supportive Ecosystem to Grow Clinical Research. Economic Transformation Programme; 2013. Available from: http://etp.pemandu. gov.my/Healthcare-@-Healthcare_-_EPP_2-;Creating_Supportive_ Ecosystem_to_Grow_Clinical_Research.aspx. Accessed September 18, 2013.

15. Philippines Pharmaceutical Country Profile. June 6, 2012. Available from: http://www.who.int/medicines/areas/coordination/Philippines_ PSCPBNarrativeQuestionnaireEndorsement_13062012.pdf. Accessed on May 13, 2014.
16. Lee YJ, Clinical Trials in Korea: Why Korea? Seoul: LSK Global Pharma Services, 2010. Available from: http://lskglobal.com/pdf/Why\%20 Korea.pdf. Accesssed April 8, 2013.

17. Virk KP. Korean Path. 2010. London: Samedan Ltd Pharmaceuticals Publishers; 2010. Available from: http://www.samedanltd.com/ magazine/13/issue/130/article/2666. Accessed April 8, 2013.

18. CPR Pharma Services Pty Ltd [homepage on the Internet]. CPR unveils Singapore's first bioanalytical laboratory. CPR Pharma Services, March 1, 2012. Available from: http://www.cprpharma.com/newsevents/latest-news?article=2602. Accessed May 15, 2013.

19. Center For Drug Evaluation, Taiwan [homepage on the Internet]. Role and Function. Taipei, Taiwan; 2006. Available from: http://www1.cde. org.tw/eng/profile/role.html. Accessed May 15, 2013.

20. Kuo Y, Hsu YM. Cross-Strait Medical and Healthcare Cooperation Agreement. International Report. London: Intellectual Asset Management; 2011. Available from: http:/www.iam-magazine.com/ reports/Detail.aspx?g=6cdaae11-f97c-49cf-8d4f-83a2dfb3d520. Accessed May 15, 2013.

21. Tuan, “August 17, 2012: Ministry of Health's guideline on CRO-SMO activities in Clinical Trial-Study in Vietnam," SMART Research, August 12, 2012. [Online]. Available from: http://www.smartresearch.com.vn/ august-17-2012-ministry-of-healths-guideline-on-cro-smo-activities-inclinical-trial-study-in-vietnam-tin-tuc-18-345.html. Accessed April 19, 2013

22. Industry Overview: Vietnam pharmaceutical Industry. Available from: http://insightalpha.com/news_test.php?cid=189\&sid=75\&nid=223. Accessed May 13, 2014.
Open Access Journal of Clinical Trials

\section{Publish your work in this journal}

The Open Access Journal of Clinical Trials is an international, peerreviewed, open access journal publishing original research, reports, editorials, reviews and commentaries on all aspects of clinical trial design, management, legal, ethical and regulatory issues, case record form design, data collection, quality assurance and data auditing

\section{Dovepress}

methodologies. The manuscript management system is completely online and includes a very quick and fair peer-review system, which is all easy to use. Visit http://www.dovepress.com/testimonials.php to read real quotes from published authors. 